\title{
Weekly rhythms in task and time allocation of households
}

\author{
Dick Ettema · Tanja van der Lippe
}

Published online: 14 February 2009

(C) The Author(s) 2009. This article is published with open access at Springerlink.com

\begin{abstract}
Analysis of household activity scheduling has to date been limited to one-day periods. This paper extends the study of household task allocation to a one-week period. Using a one-week time use survey held under couples in The Netherlands in 2003, the paper proposes indicators for measuring task allocation on a daily and weekly scale and investigates to what extent role expectations, work status and indicators of time pressure influence task allocation patterns. The outcomes suggest that egalitarian role expectations and higher female work status lead to a more balanced allocation of work and households tasks between spouses. More traditional role views and increased time pressure lead to more specialisation and inequality between spouses. Interestingly, households under time pressure apply day-to-day specialisation to arrive at balanced weekly allocation totals.
\end{abstract}

Keywords Time allocation - Task allocation - Household interactions · Specialisation

\section{Introduction}

According to the activity-based approach to travel-analysis, a proper understanding of travel behaviour requires insight in how individuals decide about activity participation and how they order these activities in space and time (Ettema 1996). Based on this notion, a wide variety of studies has been carried out, focusing on the analysis of individual daily activity patterns in relation to socio-demographic characteristics (Ma and Goulias 1997), spatial setting and transport options (Schwanen and Dijst 2001) and lifestyle aspects (Kitamura et al. 1997).

D. Ettema $(\square)$

Faculty of Geosciences, Utrecht University, PO Box 80115, 3508 TC Utrecht, The Netherlands e-mail: d.ettema@geo.uu.nl

T. van der Lippe

Department of Sociology/ICS, Utrecht University, PO Box 80140, 3508 TC Utrecht, The Netherlands e-mail: t.vanderlippe @uu.nl 
Daily individual activity patterns do, however, not take place in isolation and should be analysed in a broader perspective. First, daily activity patterns form part of weekly or monthly patterns, implying that they are the outcome of decision processes concerning longer time periods. Many of such longer-term allocation processes have been institutionalised in time regimes of firms, schools and other institutions, resulting in typical distributions of activity and time allocation on particular days of the week. To study such patterns, a few studies have recorded individuals' activity patterns for longer periods. A recent example is the German Mobidrive project (Schlich and Axhausen 2003), collecting activity and trip diaries for a six-week period. These data were used to investigate (amongst other things) the extent to which days of the week differ with respect to activity engagement and trip making (Schlich and Axhausen 2003) and the interval periods of activities such as shopping trips (Bhat et al. 2005).

A second extension to the study of individual daily activity patterns concerns the study of household interactions. Individuals' activity participation and time allocation are the outcome of a task allocation process on the household level, in which certain activities are tied to specific individuals, but others may be transferred from one person to another, for example to decrease feelings of time pressure resulting from the need to combine activities (Van der Lippe et al. 2006). Given the activities a household wishes to engage in, certain strategies will be developed to implement the required activities and to achieve household goals. Based on activity and trip diaries, various authors have found this allocation process to depend on such factors as male and female work status, human capital, the presence of (young) children, car availability and spatial characteristics (e.g. Golob and McNally 1997; Van der Lippe and Siegers 1994; Gliebe and Koppelman 2003; Ettema et al. 2007). In addition, examples are found of interaction and substitution between spouses, supporting the idea that male and female activity participation can be regarded as the outcome of an allocation process at the household level (Becker 1981).

Although substantial work has been carried out with respect to weekly (or longer term) activity patterns and household activity scheduling processes, an unexplored issue is whether weekly (or longer term) patterns exist with respect to task and activity allocation within households. For instance, if a mutual relationship is found between female paid work and male household tasks, we do not know whether this relationship holds as an average over all workdays or occurs on particular days of the week only. Generally speaking, little is known regarding the mechanisms followed by households to assign tasks and activities to their members over longer time periods. Nevertheless, such information is crucial for understanding how travel demand varies between days of the week, which has obvious implications for the design of the transportation system. Moreover, it is important to disentangle the interdependencies between spouses in activities and time use. In particular, such information will provide insight into the conditions under which neglecting multi-day and multi-person interactions leads to false outcomes.

Therefore, the aim of this paper is to explore mechanisms in time and task allocation between spouses in households during a one-week period. In addition, we intend to gain insight in the explanatory factors guiding these mechanisms.

As a first analysis we focus on weekdays, as the working week is the period where many activities (paid work, household tasks, childcare) have to be traded-off against each other. Weekly task allocation mechanisms were investigated using a 2003 Dutch database, in which spouses recorded their time allocation to all activities during one week.

The paper is organised as follows. Section "Theoretical background and analytical framework" discusses relevant literature in the area of task allocation in households and formulates hypotheses with respect to the impact of household characteristics and spatial 
context on task allocation. To this end, formal measures of multi-day variability in task allocation are introduced. Section "Data" briefly presents the data set used to test the hypotheses. Empirical findings are discussed in section "Empirical findings". In the final section, conclusions are drawn regarding weekly rhythms of task allocation and implications for travel behaviour research.

\section{Theoretical background and analytical framework}

General theory regarding task allocation

The sociological literature on time use and division of paid and domestic labour (e.g. Van der Lippe and Siegers 1994), suggests various theoretical approaches that explain how allocation patterns emerge. One school emphasises the impact of roles (Moore 1985), being gender-based expectations, held by particular groups, of how males and females should behave and spend their time. A traditional role expectation would then typically be that the male is responsible for the majority of paid labour, whereas the female focuses on household and childcare obligations. Research finds mixed support for the relation between gender roles, attitudes and behaviour (Van der Lippe and Siegers 1994; Coltrane 2000; Presser 1994; Jansen and Kalmijn 2002).

In contrast, exchange theory (Thibault and Kelley 1986; Blood and Wolfe 1960) states that task allocation is the outcome of a process in which spouses try to maximise their rewards and minimise their costs, based on their available resources. In this respect, earning capacity and wage rates of both spouses, their education and occupation are all important factors in the task allocation. There are ambiguous empirical findings as regards the relation between socioeconomic resources. Many studies show that a more equal task allocation between spouses exists when they have more comparable resources (Coverman 1985; Greenstein 2000), but there are also exceptions (Bittman et al. 2003). In contrast to role theory, exchange theory assumes more deliberate choices by spouses, in which availability of socio-economic resources is the crucial factor (Komter 1989).

Finally, new home economics (Becker 1981) assumes that instead of maximising their own rewards, spouses aim at the maximisation of a level of utility on the household level. Thus, choices regarding the division of paid and domestic labour aim at optimising the welfare of the household as a whole. A crucial issue here is how the household utility is composed of the individual utilities. Zhang et al. (2002) show that by choosing different aggregation functions, Becker-type allocation models can represent both egocentric (as in exchange theory) and altruistic strategies. Another important implication of new household economics is that it introduces time and budget constraints into the equation, implying interdependencies between spouses' time allocations. First, the budget constraint implies that a certain amount of income needs to be available to facilitate money-consuming activities. This results in a certain time that needs to be spent on paid labour, which needs to be allocated to spouses. In addition, the time constraint implies that certain obligatory activities, such as household or childcare, may need to be transferred from one spouse to another. Many studies (e.g. Golob and McNally 1997) indeed indicate that relationships exist between time expenditures to various activities of males and females. With respect to this allocation mechanism, Gliebe and Koppelman (2003) and Ettema et al. (2007) found evidence that the severity of constraints affects the degree of specialisation in the household. If time constraints are more binding (e.g. because of a poor availability of facilities, lack of transportation options or the presence of young children) households tend 
to specialise in the sense that the male focuses on paid labour, whereas the female focuses on household and childcare tasks. This reasoning is related to the time availability approach in sociology, which argues that the more time is spent in the labour market, the less time is available for care and leisure time. This expectation is based on a scarcity argument (Hiller 1984; Van der Lippe et al. 2004). Because a day 'only' has 24 hours, time for one activity implies obviously less time for another activity.

Measuring weekly rhythms in time allocation

In the above, some general mechanisms for coordinating household activity schedules were discussed. However, since our aim is to study day-to-day variability in activity patterns, the question is how these general strategies are implemented from day to day. There are various reasons to assume that variations from day to day will occur. First, time allocation is often affected by institutional contexts. For instance, elementary schools in the Netherlands are closed on Wednesday afternoon and often on Friday afternoon. This will have direct implications for the allocation of childcare and other tasks on these days. Another institutional factor concerns the high percentage of part time workers in the Netherlands $(66 \%$ of the women). As a consequence, many people work four or fewer days per week, with the free days being concentrated towards the end of the workweek (particularly Friday).

Another consideration is that a strategy such as specialisation does not necessarily have to be implemented on a weekly level. If a household favours an equal distribution of tasks but faces time constraints, this can be resolved by specialisation on a daily base. For instance, the male works on some days and the female on other days, with the non-worker taking care of all household tasks.

In order to formulate hypotheses regarding weekly allocation patterns and day-to-day variations in time allocation strategies, we will first introduce a number of measures that express the amount of variation. As a start, we distinguish between the allocation of time to a specific activity on the weekly level $\left(a_{i}^{w}\right)$ and on a particular day $d\left(a_{i}^{d}\right)$, defined as:

$$
\begin{gathered}
a_{i}^{w}=\frac{\sum_{d=1 \ldots 5} t_{i}^{d f}}{\sum_{d=1 \ldots 5}\left(t_{i}^{d m}+t_{i}^{d f}\right)} \\
a_{i}^{d}=\frac{t_{i}^{d f}}{t_{i}^{d f}+t_{i}^{d m}}
\end{gathered}
$$

where $a_{i}^{w}$ is the weekly time allocation; $a_{i}^{d}$ is the daily time allocation; $t_{i}^{d f}$ is the time spent by the female on activity $i$ on day $d ; t_{i}^{d m}$ is the time spent by the male on activity $i$ on day $d$; $d$ is the day of the week ( $1=$ Monday, $5=$ Friday $)$.

It is noted that $a_{i}^{w}$ denotes an even distribution between spouses if $a_{i}^{w}=0.5$. Values higher or lower than 0.5 increasingly point at a level of specialisation by either the male $\left(a_{i}^{w}<0.5\right)$ or the female $\left(a_{i}^{w}>0.5\right)$. To find a gender-neutral measure of specialisation, we define:

$$
s_{i}=\left|0.5-a_{i}^{w}\right|
$$

It is easily seen that a weekly time allocation $a_{i}^{w}$ can stem from different combinations of daily time allocation patterns $a_{i}^{d}$. In particular, given the weekly time allocation, the daily allocations can vary more or less around the weekly mean. To operationalise this degree of variation, the variance $v_{i}$ is defined as: 


$$
v_{i}=\frac{\sum_{d=1 \ldots 5}\left(a_{i}^{d}-a_{i}^{w}\right)^{2}}{5}
$$

Note that $v_{i}$ is operationalised on the household level to express the variation in time allocation to spouses across weekdays.

Apart from the allocation of one activity between spouses across days, it may be worthwhile to look at relationships between two activities. For instance, if spouses agree on some form of specialisation, this may imply that if one spouse spends more time on one task activity (e.g. paid work) the other spouse is likely to spend more time on another task activity (e.g. household). We may, however, expect that such interdependencies arise also on a multi-day basis. That is to say, on days that one spouse takes a larger part of activity $A$ he/she will take a smaller part of activity $B$, whereas on other days a smaller part of $A$ may coincide with a larger part of $B$. To operationalise such relationships, the covariance $c_{i j}$ is defined as:

$$
c_{i j}=\frac{\sum_{d=1 \ldots 5}\left(a_{i}^{d}-a_{i}^{w}\right)\left(a_{j}^{d}-a_{j}^{w}\right)}{5}
$$

A positive covariance thus implies that a larger (smaller) share of activity $i$ of one partner coincides with a larger (smaller) share of $j$ on the same day, whereas a negative covariance implies that larger (smaller) shares of $i$ and $j$ take place on different days. One way of interpreting the covariance is in terms of specialisation. For instance, if on one day one spouses takes care of the households tasks (and works less) while on another day the other spouse takes care of the household tasks (and works less), a form of day-to-day specialisation takes place, allowing spouses to both combine paid work with household tasks, while maintaining advantages of specialisation, such as more efficient trip planning. This would lead to a negative covariance between paid work and household tasks.

\section{Hypotheses}

Having defined the concepts of daily and weekly allocation and variance and covariance (the latter two defined at a weekly level), various hypotheses are raised regarding the factors affecting time allocation patterns. Some hypotheses concern the weekly allocation (which can be regarded the more general allocation pattern) while others concern the dayto-day variation as expressed by the variance and covariance.

1. Role theory suggests that if the male or female has traditional role expectations, the male will account for a larger share of paid labour and a smaller share of household and childcare tasks, as expressed by the indicators $a_{i}^{w}$.

2. Both exchange theory and new home economics suggest that if the male has a higher qualified job, implying a higher wage rate, he will take a larger share of paid labour and a smaller share of household and childcare tasks, reflected by $a_{i}^{w}$.

3. The time availability approach suggests that if accessibility to jobs or stores is low, or if young children are part of the household, time constraints will be more severe, resulting in task specialisation as a form of time management: the male will take a larger share of paid labour whereas the female will take a larger share of household and childcare tasks.

As noted before, for a given weekly allocation $a_{i}^{w}$, there are multiple ways in which the allocation can be realised. This can be expressed in different levels of variance $\left(v_{i}\right)$ and 
covariance $\left(c_{i j}\right)$. If the variance (and covariances) are low, daily allocation and weekly allocation are more or less the same, with little variation in the daily allocation. If the variance and covariances are high, this may point at a situation in which specialisation takes place on a daily basis. In total however, this may lead to a more or less even distribution on a weekly level. With respect to variance $v_{i}$ and covariance $c_{i j}$ the following hypotheses are formulated:

4. If a household faces more time constraints (due to the presence of young children, poor accessibility or the female working more hours) specialisation on a daily basis will occur more frequently. In particular, on one day the male will take care of household tasks and childcare (and work less) while the female does so on other days. This implies stronger negative covariances $c_{i j}$ between paid work-household tasks and paid work-childcare and a stronger positive covariance between household tasks and childcare. For all activities, variances $v_{i}$ will be larger.

5. If a household has traditional role expectations, the specialisation reflected in $a_{i}^{w}$ is more likely to take place on all days. Specialisation on a day-to-day basis as a time management tool is less necessary. Therefore, variances $v_{i}$ and covariances $c_{i j}$ will be smaller.

6. If the working status of the male is higher, he will focus more on paid labour and take a smaller share of household and childcare tasks. Specialisation will occur on a weekly level more than on a day-to-day basis. Therefore, variances $v_{i}$ and covariances $c_{i j}$ will be smaller.

7. If the working status of the female is higher, both spouses need to combine paid labour with household and childcare tasks with higher time constraints. Specialisation on a day-to-day basis is expected with higher variances $v_{i}$ and covariances $c_{i j}$.

Regarding the relationship between variances/covariances on the one hand and weekly allocation on the other hand, it is noted that a relationship exists from a mathematical point of view: if variance is high, this implies that one spouse takes low and high shares of an activity on different days, increasing the probability that on a weekly level, the allocation is more even. Thus, if the variance is higher, the specialisation on a weekly basis (which can be expressed in a standardised form as $\left.\left|a_{i}^{w}-0.5\right|\right)$ will be less. Although this relationship is partly a corollary from the definitions, it is related to deliberate decision-making, and therefore worth testing. In particular, we can hypothesize (hypothesis 8) that day-to-day specialisation is applied with the intention to realise a more even task allocation on the weekly level. If this is the case, a negative relationship between day-to-day specialisation (covariance between paid work and household tasks) and weekly specialisation is expected.

\section{Data}

The hypotheses were tested on a data set collected as part of the Time Competition project (Van der Lippe and Glebbeek 2003), aiming at the investigation of household and employment relationships. Data were collected by means of a multistage sample of employees of 30 Dutch firms, hence only households in their working years are included. Home interviews were conducted with 1,114 employees and, if applicable, their partners at a response rate of $29 \%$. We focus on couple households, leaving 819 cases. Both partners were interviewed and filled in written questionnaires. After excluding cases with missing values on our main explanatory and dependent variables, eventually 740 cases are included in the analyses (323 couples with children under age 10 in childcare analyses). 
Apart from questions regarding usual socio-demographic variables, the questionnaire contained detailed questions with respect to work organisation and role expectations. Also, both spouses were requested to report their time expenditures to a variety of activities for seven consecutive days. For the purpose of our study we defined broader categories of activities as follows:

- paid work (also when carried out at home)

- household tasks (cooking, making table, cleaning, washing, ironing)

- childcare (washing, feeding, dressing, playing, reading, dropping off, helping with homework)

- leisure (clubs, churches, etc., going out, reading, watching TV, sports funshopping etc.)

In the context of the theoretical framework, it is noted that issues such as specialisation and task allocation especially relate to paid work, household and childcare tasks. However, these activities in turn may compete with other activities, such as the broad category termed 'recreation' in this study. To investigate such competition effects, the 'recreation' category will also be included in the analysis.

Based on a factor analysis, two role expectation variables were defined as function of the responses of female respondents to various theses:

$$
\begin{aligned}
& \text { F-traditional }=T 1-T 2+T 3+T 4 \\
& \text { F-egalitarian }=T 5+T 6
\end{aligned}
$$

where $T 1$, A woman is better fit to raise little children than a man; T2, I find it quite normal if a girl follows technical education; T3, It is natural that the male is the breadwinner and the woman takes care of the household and the children; T4, It is unnatural if women in a firm are in charge of men; T5, Both partners should spend the same a mount of time to tasks at home; T6, Both partners should have the same amount of leisure time.

Based on respondents' postal code, the data was enriched with spatial data. In particular, the number of inhabitants and jobs within $15 \mathrm{~min}$ by car, the number of stores within $5 \mathrm{~min}$ by car were used as additional explanatory variables. It is noted that a wide range of accessibility variables were tested, including contour measures of job and population accessibility with different travel modes and travel time thresholds, as well as various zonal characteristics such as population density and the number of jobs in seven economic sectors. Since these spatial indicators are partly overlapping, we used those that appeared to have the largest impact on patterns of task and time allocation. In general, spatial factors did appear to play a limited role compared to personal and household characteristics, probably due to the generally high accessibility to services in The Netherlands. It is further noted that since the data set was designed to investigate time use patterns and household interactions rather than travel behaviour, variables common to transportation studies, such as car ownership and the location of children's schools were missing. A general indication of commute length (in terms of duration), however, was included.

Finally, various explanatory variables were transformed to dichotomous variables to allow us to test hypotheses regarding the effect of the variables in a straightforward way. The definition of the dummy variables and their linkage to hypotheses are given in Table 1. In case of accessibility measures, thresholds were set such as to represent the $20 \%$ households with the best accessibility.

With respect to the sample composition, slightly more than $70 \%$ of all couples in our sample are married. There is an intentional overrepresentation of dual earner couples in the sample, because the data were collected specifically to study the causes of and solutions to 
Table 1 Definition of dummy variables

\begin{tabular}{lll}
\hline Variable & Description & Related to hypothesis \\
\hline F-trad & F-traditional $>9$ & 1,5 \\
F-egal & F-egalitarian $>5$ & 1,5 \\
M-heduc & Male education is higher professional or academic & 2,6 \\
F-heduc & Female education is higher professional or academic & 2,7 \\
High-acc-pop & \# Of inhabitants within 15 min by car $>470.000$ & 3,4 \\
High-acc-job & \# Of jobs within 15 min by car $>233.000$ & 3,4 \\
High-acc-ret & \# Shops 5 min by car $>1,260$ & 3,4 \\
M-long-com & Male commute time $>30$ min & $2,3,4$ \\
F-long-com & Female commute time $>30$ min & $2,3,4$ \\
M-manag & The male has a management position & 2,6 \\
F-manag & The female has a management position & 2,7 \\
Young-kid & The household contains a child younger then 10 years & 3,4 \\
\hline
\end{tabular}

work-home interference. As a consequence, the respondents' educational level is relatively high as well; $57 \%$ of the respondents have some college or more compared to $28 \%$ nationally.

\section{Empirical findings}

The hypotheses were tested by various analyses. Hypotheses 1-3, which address general (or average) allocation patterns were tested by investigating the average level of task allocation to various activities $\left(a_{i}^{w}\right.$ or $\left.a_{i}^{d}\right)$ and the factors affecting the average, using linear regression models. Hypotheses 4-7, which address weekly allocation patterns, are tested by investigating variances $\left(v_{i}\right)$ and covariances $\left(c_{i j}\right)$ and the factors impacting on them, using linear regression analysis. Hypothesis 8 was tested by examining the level of specialisation and the factors affecting it (including variance) using linear regressions.

In these regression models, personal and household characteristics, such as household composition, education level, career type, role expectations, commute length and accessibility variables were used as explanatory variables (Table 1). These variables allow us to test the hypotheses about the impact of household characteristics and spatial factors on their coping strategies. Regression models were estimated in a stepwise fashion, so that Tables 3, 4 and 5 only display significant parameters. Note that in an earlier stage a wider range of spatial variables were tested in the regression models, but that they did not appear to significantly explain time and task allocation indices. The tables also display the sample mean of time allocation, variance and covariance. Overall, the goodness-of-fit of the models is quite low, although most are significant according to an ANOVA. Nevertheless, they provide insight as to which socio-demographic variables affect task allocation.

Task allocation by day of the week and weekly total

Table 2 displays the task allocation patterns to various activities by day of the week. Table 3 shows the outcomes of the regression analyses in which weekly allocation $\left(a_{i}^{w}\right)$ for each activity serves as the dependent variable. 
Table 2 Mean task allocation by day of the week for various activities

\begin{tabular}{lllllll}
\hline & $a_{i}^{\text {Monday }}$ & $a_{i}^{\text {Tuesday }}$ & $a_{i}^{\text {Wednesday }}$ & $a_{i}^{\text {Thursday }}$ & $a_{i}^{\text {Friday }}$ & $a_{i}^{w}$ \\
\hline Work & 0.400 & 0.395 & 0.339 & 0.381 & 0.337 & 0.391 \\
Household & 0.653 & 0.656 & 0.683 & 0.675 & 0.665 & 0.676 \\
Childcare & 0.620 & 0.628 & 0.648 & 0.647 & 0.614 & 0.624 \\
Leisure & 0.501 & 0.490 & 0.505 & 0.494 & 0.498 & 0.514 \\
\hline
\end{tabular}

Table 3 Regression models of allocation of time

\begin{tabular}{|c|c|c|c|c|}
\hline & $a_{\text {work }}^{w}$ & $a_{H H}^{w}$ & $a_{c h}^{w}$ & $a_{l e}^{w}$ \\
\hline Constant & $\begin{array}{l}0.350 \\
(20.259)\end{array}$ & $\begin{array}{l}0.687 \\
(37.764)\end{array}$ & $\begin{array}{l}0.652 \\
(37.139)\end{array}$ & $\begin{array}{l}0.475 \\
(51.747)\end{array}$ \\
\hline Young-kid & $\begin{array}{l}-0.034 \\
(-2.484)\end{array}$ & & & \\
\hline M-manag & $\begin{array}{l}-0.055 \\
(-4.017)\end{array}$ & $\begin{array}{l}0.047 \\
(3.096)\end{array}$ & $\begin{array}{l}0.045 \\
(2.148)\end{array}$ & $\begin{array}{l}0.027 \\
(2.703)\end{array}$ \\
\hline M-long-com & & $\begin{array}{l}0.031 \\
(1.998)\end{array}$ & & $\begin{array}{l}0.030 \\
(2.861)\end{array}$ \\
\hline M-heduc & $\begin{array}{l}0.031 \\
(2.247)\end{array}$ & $\begin{array}{l}-0.059 \\
(-3.829)\end{array}$ & & \\
\hline F-manag & $\begin{array}{l}0.058 \\
(3.692)\end{array}$ & & $\begin{array}{l}-0.084 \\
(-3.330)\end{array}$ & \\
\hline F-long-com & $\begin{array}{l}0.082 \\
(5.281)\end{array}$ & $\begin{array}{l}-0.081 \\
(-4.595)\end{array}$ & $\begin{array}{l}-0.068 \\
(-2.724)\end{array}$ & $\begin{array}{l}-0.040 \\
(-3.486)\end{array}$ \\
\hline F-trad & $\begin{array}{l}-0.054 \\
(-3.757)\end{array}$ & $\begin{array}{l}0.044 \\
(2.755)\end{array}$ & & \\
\hline F-heduc & & & & $\begin{array}{l}0.025 \\
(2.443)\end{array}$ \\
\hline F-egal & $\begin{array}{l}0.042 \\
(3.046)\end{array}$ & $\begin{array}{l}-0.078 \\
(-5.044)\end{array}$ & & \\
\hline High-acc-ret & & & $\begin{array}{l}-0.076 \\
(-2.609)\end{array}$ & \\
\hline Adjusted $\rho^{2}$ & 0.157 & 0.116 & 0.069 & 0.040 \\
\hline
\end{tabular}

$t$-values in parentheses

\section{Paid work}

For the allocation of paid work we find in Table 2, that on all days, the share of paid work accounted for by women is less than half, but is especially lower on Wednesdays and Fridays. This finding can be understood from the large percentage of Dutch women working part time $(66 \%)$. Wednesdays and Fridays are especially the days on which part timers do not work.

Looking at the segmentation variables (Table 3), we find that if the male has a management position, the share of paid work accounted for by the female decreases. This is due to the male spending more time on paid work. As expected, we find that if the female has a management position, (or has a long commute, often coinciding with a higher qualified job) her share of the work activity is significantly higher. Both outcomes support Hypothesis 2, which states that with a higher economic status the partner takes a larger 
share of paid work, since availability of more resources increases the bargaining position in the household.

Table 3 further suggests that females with traditional role expectations account for a smaller part of paid work in the household. Women in favour of equal distribution of tasks account for a larger share of the paid work. Both findings support hypothesis 1, implying the importance of role expectations in task allocation. Also the fact that a higher education of the male leads to a more even distribution of paid work supports this hypothesis.

The fact that in the presence of young children, women account for a smaller share of paid work is in line with the specialisation implied by the time availability approach (Hypothesis 3). Time pressure then invokes specialisation within the household with males focusing on paid labour and women specialising in household tasks.

\section{Household tasks}

Table 2 suggests that the share that females take from the time spent on household tasks is rather stable at $65-68 \%$ across weekdays.

The regression results suggest that if the male has a management position, the share of household work taken care of by women increases. In reverse, if the female has a longer commute, suggesting a higher qualified job, she takes care of a smaller part of the household tasks. Both findings are in line with exchange theory, suggesting that a partner with increasing earning capacity, accounts for more of the paid labour, and consequently for less of the household tasks.

If the male is highly educated, this leads to a more equal distribution of household tasks. In addition, Table 3 suggests that women with traditional role expectations account for a larger part of household tasks. Women having a positive attitude toward an equal distribution of tasks within the household account for a smaller part of household tasks on all days. Taken together, these findings support the importance of role expectations in allocating household tasks. If the spouses have less traditional and more egalitarian role expectations household tasks will be allocated more equally, with the female accounting for less of it than in more traditional households.

Finally, it is found that males account for a larger and females for a smaller part of household tasks if they have a long commute. For men, this supports role theory, in the sense that men with longer commutes are higher educated and apparently have more egalitarian role expectations. For women, the similar reasoning would hold. In addition, this finding is in line with the impact of time constraints on task allocation as suggested by the time availability approach.

\section{Childcare}

Childcare is taken care of mostly by women, on all weekdays, with the percentage varying between 61 and $65 \%$.

Regarding the factors affecting task allocation, we find that a management position of the male leads to a higher share of the childcare done by the female. However, if the female has a management position, she accounts for a smaller part of childcare. Both findings support the role of socio-economic status suggested by exchange theory.

Somewhat surprisingly, having traditional role expectations or being in favour of equal task distribution does not affect the distribution of childcare tasks. Probably, childcare is an obligatory activity, implying less freedom in the allocation of tasks based on role preferences. 
Table 3 further suggests that in areas with a high accessibility of stores, the share of childcare by females is less. A potential explanation is that areas with a higher concentration of facilities make it easier to combine tasks, thus leading to less specialisation and a higher male share of childcare activities. We further find that a longer commute distance leads to a smaller share of the childcare activities being taken care of by the female, highlighting the importance of time constraints.

\section{Leisure}

In general, Table 2 suggests that leisure time is on average equally distributed between spouses on all weekdays. With respect to variables influencing the allocation, Table 3 suggests that if the male has a management position, the female accounts for a larger part of leisure time, probably due to less time being available for the male to engage in leisure. In contrast, a management position of the female does not lead to a change in the allocation of leisure time. Further, we find that if the female is highly educated, she takes a larger share of the leisure time.

A longer male commute time coincides with a larger share of the leisure time being taken by the female, again due to less time for leisure remaining for the male. Likewise, a longer female commute leads to a smaller share of the leisure time by the female.

\section{Conclusion}

A clear task allocation pattern is observed for the couples in the sample. On average, the male accounts for the majority $(61 \%)$ of paid work time, whereas the female accounts for the majority of household tasks $(68 \%)$ and child care tasks $(62 \%)$. This task allocation pattern is affected by various factors, largely confirming the Hypotheses 1-3. Supporting role theory, it is found that women with traditional role expectations account for a smaller part of paid work and a larger part of household tasks. The reverse is found for women with egalitarian role expectations. Supporting exchange theory and new home economics, it is found that if the male or female has a higher economic status, he/she will work relatively more and accounts for less of the household and child care tasks. If time constraints are more severe (due to the presence of children) this leads to a form specialisation where the male specialises in working and the female in household tasks and childcare. This finding confirms Hypothesis 3. Taking into account that a large variety of spatial factors, such as accessibility to jobs or stores in various specifications were tested, it might be concluded that they hardly affect task allocation. A possible explanation for this finding is that in the Netherlands, retail planning has placed a strong emphasis on accessibility, resulting in stores being available on relatively short distance for every place in the Netherlands. Thus, store accessibility is not a major issue in task allocation. With respect to job accessibility, it is noted that the decision where to work is not primary driven by distance minimisation but rather by job type and career opportunities. Also the fact that dual income households have to balance their residential location relative to two work places might make job accessibility a less relevant factor.

Variance and covariance in time and task allocation

As mentioned previously, households may employ different strategies in order to fulfil various household tasks. We have hypothesized that if time constraints become more 
binding, spouses tend to specialize in either paid work or household and childcare tasks, which was supported by the analyses. However, this specialization may pertain to all weekdays similarly, or vary between days. If the first is the case, variances in time allocation (within households over weekdays) will be small. If the latter is the case, variances will be larger. An example would be the case where partners in an alternating way account for household tasks (and consequently work less) on consecutive days. Such a case allows spouses to both be engaged in paid work, while maintaining the organisational advantages of specialisation. We will term this strategy day-to-day specialisation, as discussed before. Recall that a form of day-to-day specialisation is supposed to lead to larger variances, to negative covariances between paid work and household tasks and between paid work and childcare, and positive covariance between household and child care. In the remainder of this section, we will discuss the variances as observed in the data for various segments.

\section{Variances and covariances}

Table 4 displays the variances and covariances. Although it is difficult to interpret the size of the variance, it is noted that the variance of paid work, household tasks and childcare is larger than the variance of leisure, suggesting a more stable allocation pattern across days for leisure. On average, we find negative covariances between paid work and household tasks and between paid work and childcare and a positive covariance between household tasks and paid work. These covariances suggest that on average, a form of day-to-day specialisation takes place, in which partners take care of household and childcare tasks in an alternating way.

Regarding the factors impacting on variances and covariances, the regression analyses suggest that the presence of young children leads to stronger (negative) covariances between paid work and households tasks and between paid work and childcare. Also the variances of paid work and household increase. This supports Hypothesis 4, stating that day-to-day specialisation is applied in response to increasing time constraints. Thus, the presence of children leads to a higher degree of day-to-day specialisation, where one spouse takes care of household and childcare task on some days and the other spouse on other days.

Hypothesis 5 states that in traditional households, day-to-day specialisation is less applied since a constant specialisation is applied, leading to smaller covariances and variances. This hypothesis is supported by the findings that if the female has an egalitarian role expectation, the variance in paid work allocation is larger as well as the covariance between household and childcare. Also, if the male is highly educated (assumed to be related to egalitarian expectations) variances in household and childcare allocation are larger.

Hypothesis 6, stating that a higher work status of the male leads to less day-to-day specialisation, was not supported, since this factor was not significant in the linear regression.

Hypothesis 7, stating that a higher work status of the female leads to more day-to-day specialisation, is supported by the higher variances for paid work (if higher educated), household tasks and childcare (if a long commute), and the stronger covariances between paid work, household tasks and childcare in case the female has a management position or has a higher education.

To summarise, the variances and covariances that are found suggest that day-to-day specialisation appears to take place for the households in the sample. The degree of day-to- 


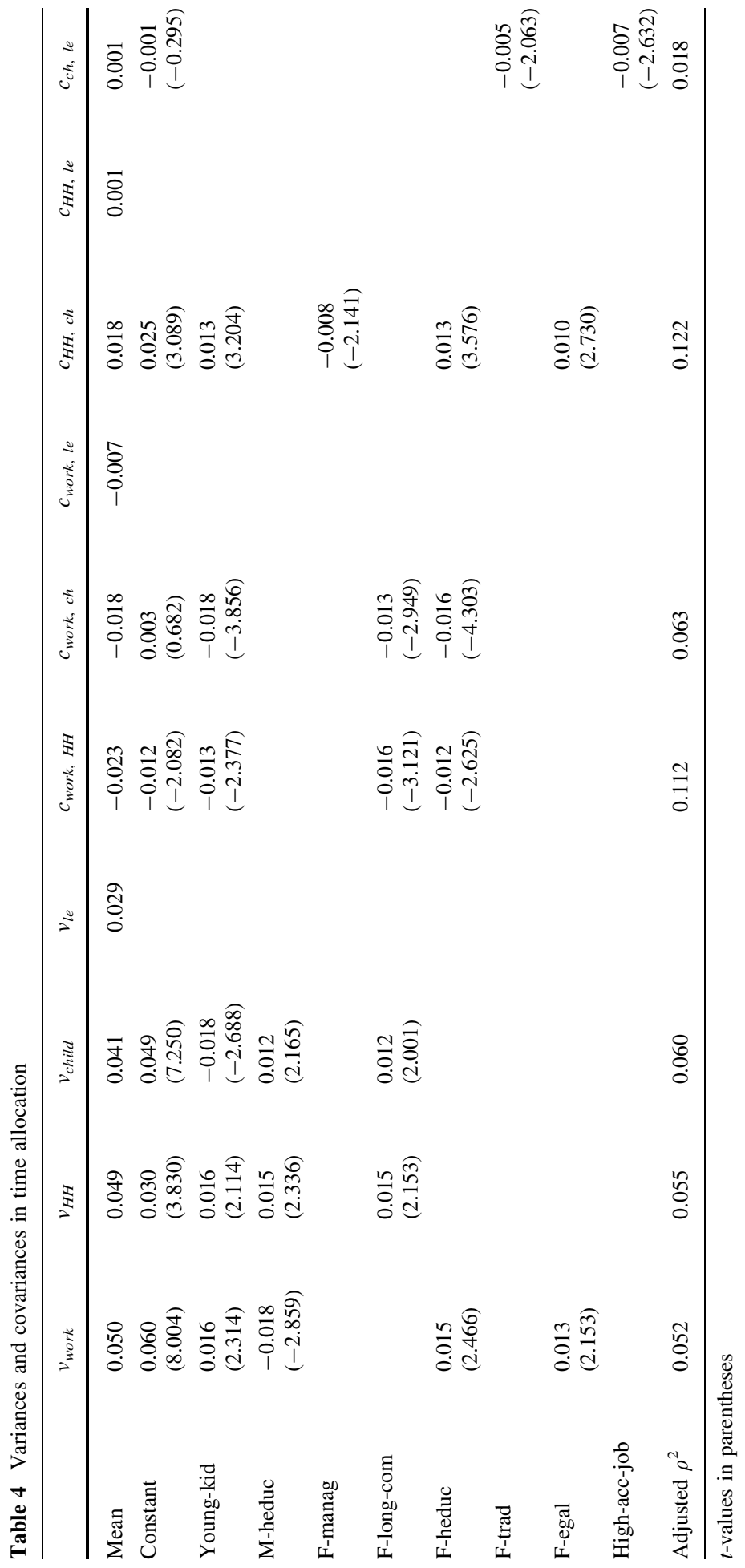


Table 5 Regressions of specialisation level for various activities

\begin{tabular}{lllll}
\hline & $s_{\text {work }}$ & $s_{H H}$ & $s_{c h}$ & $s_{l e}$ \\
\hline Constant & 0.215 & 0.348 & 0.310 & 0.146 \\
& $(10.468)$ & $(16.828)$ & $(9.582)$ & $(6.366)$ \\
M-heduc & -0.009 & -0.007 & -0.001 & -0.003 \\
& $(-4.547)$ & $(-2.933)$ & $(-0.376)$ & $(-1.798)$ \\
F-heduc & -0.004 & -0.005 & 0.000 & -0.002 \\
& $(-1.877)$ & $(-2.340)$ & $(-0.122)$ & $(-0.912)$ \\
F-manag & & & & -0.016 \\
Young-kid & 0.040 & & -0.081 & 0.020 \\
F-egal & $(4.137)$ & & $(-4.663)$ & $(2.729)$ \\
& & -0.051 & & \\
High-acc-pop & & $(-5.051)$ & & -0.006 \\
& & -0.027 & & $(-0.054)$ \\
$v_{i}$ & $(-2.269)$ & -0.931 & 0.022 \\
Adjusted $\rho^{2}$ & $(-0.364$ & -1.128 & $(-6.087)$ & 592 \\
$n$ & 0.079 & $(-11.525)$ & 0.151 & \\
\hline
\end{tabular}

$t$-values in parentheses

day specialisation increases in case of time constraints (e.g. through the presence of young children), egalitarian role expectations and a higher female work status.

Day-to-day specialisation and weekly specialisation

Hypothesis 8 states that day-to-day specialisation can be applied as a way to avoid weekly specialisation. That is to say, if the spouses specialise in different activities on different days, the household will benefit from the effectiveness of specialisation while both spouses are able to combine paid work and household tasks. If this is the case, one would expect that higher levels of day-to-day specialisation (coinciding with higher variances) coincide with lower levels of weekly specialisation. To test this hypothesis, regression analysis were carried out in which the weekly specialisation index (Eq. 3) was used as the dependent variable. The variance was used as explanatory variable, while controlling for a series of socio-demographic variables.

The regression results in Table 5 suggest that in case of paid work, household tasks and childcare, the variance (representing the day-to-day specialisation) is negatively related to the weekly specialisation. This supports the hypothesis that day-to-day variation is used as a way to achieve (or maintain) a more even allocation of tasks/activities between spouses. Other important factors for describing the degree of specialisation are education level and egalitarian role expectations.

\section{Conclusions}

In this paper, we have investigated rhythms in spouses' task allocation patterns and strategies on a weekly and day-to-day level. Using a 2003 data set of spouses' time use, we 
have tested hypotheses regarding the effects of various variables on time allocation strategies.

With respect to the explanation of paid and household labour, our results confirm findings of earlier studies. Supporting role theory, it is found that women with traditional role expectations account for a smaller part of paid work and a larger part of household tasks. The reverse is found for women with egalitarian role expectations. Supporting exchange theory, it is found that if the male or female has a higher economic status, he/she will work relatively more and accounts for less of the household and child care tasks. If time constraints are more severe (due to the presence of children) this leads to a form specialisation where the male specialises in working and the female in household tasks and childcare. This finding confirms Hypothesis 3. Spatial factors, such as accessibility to jobs or stores do not affect task allocation.

With respect to the hypothesis that households respond to increased time pressure by a specialisation on a day-to-day basis, we find that the presence of children leads to higher variances in the allocation of paid work, household tasks and childcare and higher covariances between these activities, suggesting that a day-to-day specialisation is indeed applied as a time management tool. We also find proof of this strategy being applied to a larger extent if the female has a higher work status and if the male is higher educated. As expected, a traditional role expectation decreases the covariance between household tasks and childcare, whereas an egalitarian attitude increases the covariance.

Finally, the hypothesis that day-to-day specialisation is used as a way to avoid overall, weekly specialisation and thus allow both spouses to combine paid work and household tasks, is confirmed in our analyses.

Overall, our results suggest that factors such as the presence of children, role expectations, work status and accessibility affect the division of paid and domestic labour in a way already reported in other studies. More importantly, we find that task allocation patterns on consecutive days are interrelated for specific groups, in the sense that a day-today specialisation exists. This implies that daily activity patterns are the outcome of a longer-term planning and allocation process, resulting in activity patterns that vary from day to day. Our results suggest that it is of great value to disentangle activities for specific days in addition to the focus on a whole week. Given the need to improve our understanding and prediction of day-to-day variations in travel demand, more research should be carried out into the exact longer-term allocation mechanisms. Ideally, such research should be based on data collected over a longer period of time than a week. Moreover, more specific mobility and travel diaries are to be included in such a new datacollection, to enable the investigation of the impact of car availability and school locations on spouses' task allocation behaviour. The results also show the importance of collecting data at the household level, since time use of both spouses is clearly interdependent.

Another related issue of interest will be to study the influence of changes over the life course on task allocation patterns of partners more closely. Whereas the current study has identified mechanisms that are at play for working couples, these mechanisms are not necessarily similar for e.g. elderly couples. In particular, factors that are relevant for younger couples (time pressure, working status, childcare) are much less or not relevant for elderly couples. Consequently, one would expect mechanisms such as daily or weekly specialisation to appear much less. From a theoretical point of view, it may be expected that exchange theory is less suited to explain task allocation, since paid labour and childcare have become irrelevant. However, new home economics and role theory might still apply to a situation where mainly household task, leisure tasks and social activities/ personal business are being planned, and joint activities will be more frequent. Overall, one 
might expect that the lack of time pressure makes the process of activity engagement less the outcome of an allocation process and more of a joint decision making process. This, combined with a process of aging of the population in many countries warrants research into the transport decision making of elderly couples.

Acknowledgements The use of Time Competition Survey data set was kindly permitted by the Time Competition Research Group of the Universities of Utrecht and Groningen. The data collection was financed by the Netherlands Organisation for Scientific Research (NWO).

Open Access This article is distributed under the terms of the Creative Commons Attribution Noncommercial License which permits any noncommercial use, distribution, and reproduction in any medium, provided the original author(s) and source are credited.

\section{References}

Becker, G.S.: A Treatise on the Family. Harvard University Press, Cambridge (1981)

Bhat, C.R., Srinivasan, S., Axhausen, K.W.: An analysis of multiple interepisode durations using a unifying multivariate hazard model. Transp. Res. B 39, 797-823 (2005)

Bittman, M., England, P., Folbre, N.: When does gender trump money? Bargaining and time in household work. Am. J. Sociol. 109, 186-214 (2003)

Blood, R.O., Wolfe, D.M.: Husbands \& Wives: the Dynamics of Married Living. The Free Press of Glencoe, IL (1960)

Coltrane, S.: Research on household labor: modeling and measuring the social embeddedness of routine family work. J. Marriage Fam. 62, 1208-1233 (2000)

Coverman, S.: Explaining husband's participation in domestic labor. Sociol. Q. 26, 81-97 (1985)

Ettema, D.: Activity based travel demand modelling. Unpublished PhD Thesis, Eindhoven University of Technology (1996)

Ettema, D., Schwanen, T., Timmermans, H.: The effect of locational, mobility and socio-demographic factors on task and time allocation in households. Transportation 34, 89-105 (2007)

Gliebe, J.P., Koppelman, F.S.: A model of joint activity participation between household members. Transportation 30, 49-72 (2003)

Golob, T.F., McNally, M.G.: A model of activity participation and travel interactions between household heads. Transp. Res. B 31, 77-194 (1997)

Greenstein, T.N.: Economic dependence, gender and the division of labor in the home: a replication and extension. J. Marriage Fam. 62, 322-335 (2000)

Hiller, D.V.: Power dependence and division of family works. Sex Roles 10, 1003-1019 (1984)

Jansen, M., Kalmijn, M.: Investments in family life: the impact of value orientations on patterns of consumption, production and reproduction in married and cohabiting couples. In: Lesthaeghe, R. (ed.) Meaning and choice: value orientations and life course decisions, pp. 129-159. Nidi/CBGS Publications, The Hague/Brussels (2002)

Kitamura, R., Mokhtarian, P.L., Laidet, L.: A micro-analysis of land use and travel in five neighbourhoods in the San Francisco Bay Area. Transportation 24, 25-158 (1997)

Komter, A.: Hidden power in marriages. Gend. Soc. 3, 187-216 (1989)

Ma, J., Goulias, K.: A dynamic analysis of person and household activity and travel patterns using data from the first two waves in the Puget Sound Transportation Panel. Transportation 24, 309-331 (1997)

Moore, J.C.: Role enactment and self identity. In: Berger, J., Morris, Z. (eds.) Status Rewards and Influence: how Expectations Organize Behaviour. Jossey-Bass, San Francisco (1985)

Presser, H.B.: Employment schedules among dual-earner spouses and the division of household labor by gender. Am. Sociol. Rev. 59, 348-364 (1994)

Schlich, R., Axhausen, K.W.: Habitual travel behaviour: evidence from a six-week travel diary. Transportation 30, 13-36 (2003)

Schwanen, T., Dijst, M.: Travel behaviour in Dutch monocentric and policentric urban systems. J. Transp. Geogr. 9, 173-186 (2001)

Thibault, J.W., Kelley, H.H.: The Social Psychology of Groups. Transaction, New Brunswick (1986)

Van der Lippe, T., Glebbeek, A.: Codebook Time Competition. Department of Sociology, Utrecht University, The Netherlands (2003) 
Van der Lippe, T., Siegers, J.J.: Division of household and paid labor between partners: effects of relative wage rates and social norms. Kyklos 47, 109-136 (1994)

Van der Lippe, T., Tijdens, K., De Ruijter, E.: Outsourcing of domestic tasks and time-saving effects. J. Fam. Issues 25, 216-240 (2004)

Van der Lippe, T., Jager, A., Kops, Y.: Combination pressure: the paid work-family balance of men and women in European countries. Acta Sociol. 49, 303-319 (2006)

Zhang, J., Timmermans, H., Borgers, A.: A utility-maximizing model of household time use for independent, shared and allocated activities incorporating group decision mechanisms. Transp. Res. Rec. 1807, $1-8$ (2002)

\section{Author Biographies}

Dick Ettema is associate professor at the Department of Human Geography and Planning of Utrecht University. His research interests include analysis and modelling of time use and activity patterns in relation to household interactions, social networks and technological developments. He also investigates the relationship between activity patterns and longer-term mobility decisions regarding residence, work status and car ownership.

Tanja van der Lippe is professor of Sociology of Households and Employment Relations at the Department of Sociology of Utrecht University. Her research interests lie in the area of work-family linkages in Dutch and other societies and include time use over the life course, gender and organisation, and international comparisons of household and employment issues, for which she received a number of large scale grants from Dutch and European Foundations. She has published extensively in both European and American journals and books in household and employment issues in Western and Eastern European countries. 